\title{
Indigenising the Curricula in Ethiopia from a Gamo Ethnic Group Perspective: The Case of Constitutional, Policy and Strategy Provisions
}

\author{
Yishak, DM \\ University of South Africa, 47016787@mylife.unisa.ac.za
}

Gumbo, MT

\section{Doi:10.5901/mjss.2014.v5n10p185}

University of South Africa, gumbomt@unisa.ac.za

\begin{abstract}
Ethiopia's ethnic federalism was introduced when EPRDF came to power in 1991 after overthrowing the Derg regime. The country's constitution and important policy and strategy documents were promulgated in order to promote the indigenisation of basic education curricula, from an ethnic group perspective in the post $1991 \mathrm{era}$. In this paper we will, thus, critically analyse the country's constitution and other important policy and strategy documents related to the indigenisation approach. The study used a qualitative case study approach and design. Findings of the study revealed that the country's constitution, policies and strategies have a number of salient provisions that support the indigenisation approach. However, there are still provisions that are aligned to the standardisation thesis, which is an antithesis to indigenisation and the blended indigenisation approach. Finally, based on the findings, it is recommended that these provisions should favour either the standardisation thesis or a stand-alone indigenisation approach, which would allow for an environment that will pave the way for an intercultural dialogue among equals.
\end{abstract}

Keywords: indigenisation, basic education, relevant education, relevant and functional curriculum, socio-cultural context

\section{Introduction}

In Ethiopia different attempts have been made by different regimes to reform the education system since the inception of modern Western education in 1908. Each of the reform endeavours criticised the preceding education system and formulated new policies to underpin the anticipated change. The major purpose of each educational reform was to make the school curriculum relevant to the learners' cultures (Temechegn, 2000). However, despite the reform attempts that went into making the curricula relevant in the different eras, the curricula remained irrelevant to the culture, history and heritage of indigenous Ethiopians.

During the Imperial and Derg regimes clear education policies were not adopted. However, two attempts at educational reform were made by both regimes. The Education Sector Review (ESR) and the Evaluative Research on the General Education System of Ethiopia (ERGESE) were carried out in 1972 and 1983, respectively. Unfortunately, the recommendations of both reform efforts were never implemented, but were rather shelved (Solomon, 2008). The present education and training policy was adopted as an extension to these two unsuccessful reform attempts by the Imperial and Derg regimes.

In this paper we address the problem of ambiguity in the constitutions, policies and strategies of the country, in the post 1991 era, regarding the promotion of the indigenisation approach in curriculum development. Today, the provisions that underpin the present process of indigenisation of the curricula, from an ethnic group's perspective, are not found in a single policy document, but are dispersed in constitutional, policy and strategy documents. Thus, our aim is to critically analyse the constitutional, policy and strategy documents that underpin the present curriculum reform in Ethiopia and suggest policy revisions which could give greater recognition to the indigenous peoples of the country.

This study is situated within the African critical theory paradigmatic position (Rabaka, 2009), because approaches to curriculum construction and change as a contextualised social process are located within this paradigm (Cornbleth, 1990; Kincheloe, 2006). The valuing of notions of multiple perspectives, known as multilogicality and epistodiversity, which counters the ethnocentrism of positivism, must always be critically grounded (Kincheloe, 2006). In maintaining this critical stance, we first review related literature which is pertinent to the issue under investigation. Next, we discuss the methodology of the study. Thereafter, we present and critically analyse the relevant information contained in the federal and regional constitutions and other important policy documents. Finally, we make pertinent conclusions and recommendations based on the findings of the study. 


\section{Review of Related Scholarship}

\subsection{The historical context of curricular reforms in Ethiopia}

In Ethiopia attempts were made to ethiopianise the education system at primary school level in 1947 and in the 1960s (from 1964 to 1974). The reforms were focused on changing the medium of instruction, the textbook language and the involvement of Ethiopian personnel in the process of curriculum development and implementation (Solomon, 2008). The reforms attempts brought about significant progress, to the extent that English was replaced with Amharic, both in primary and secondary education, during the Derg regime (Tekeste, 2006). However, the Ethiopianisation or indigenisation of education at national level can be considered an affirmation of the assimilation policy, which was publicly opposed by the subjugated ethnic groups who initiated the creation of ethnic movements and led armed revolts in various regions of the empire-state (Teklehaimanot, 1999; Kassam, 2002; Habtu, 2003).

The post-1991 era heralded the onset of a new political order known as ethnic federalism, which is based on ethnic groups as the constituent units and foundations of the federal state (Habtu, 2003; Tekeste, 2006; Lovise, 2011). The basic education curriculum was aligned to the political, marking the beginning of indigenisation from an ethnic group's perspective (Tekeste, 2006; Yishak \& Gumbo, 2012). Girma (2012) drew a parallel between the ethno-federalist approach to education in Ethiopia and the postmodernist way of thinking, suggesting that both claim to make the issue of ethnic minority an important part of their moral discourse.

\subsection{Determinants of the relevance of education and the curriculum}

Education is relevant and effective when it is built on appreciation of the cultural heritage of the people (Tekeste, 1996); grounded in the actual community life of the people and gives due recognition to their indigenous knowledge and learning systems (Alangui, 1999); based on sound and culturally-inclusive social philosophies that are reflective of the lives of the people (Abdi, 2009); anchored in the cultural experience and the historical and cultural knowledge of the people (Dei, 2008); and incorporates the social, technological, economic and psychological life of the society into the schools and the curricula (Amare, 2009a).

Educational relevance is shaped by a relevant and functional curriculum and pedagogy, which is extracted from the culture of the people (Salia-Bao, 1989; Dei, 2008). The relevance and functionality of the curriculum is, in turn, dictated by its relation to the culture, livelihoods, values and psychological make-up of the society (Amare, 2009b); its rootedness in the culture, environment and needs of the people; its grounding in the philosophy, politics, and economy of the society (Salia-Bao, 1989); and its alignment to the social structure to which the students belong (Shiundu \& Omulando, 1992). Cornbleth (1990) has come up with a notion known as "curriculum in context", which concurs with Kincheloe's (2008) critical complex epistemology, and advocates that there is an inseparable link between knowledge and context. Shizha (2006) and Sleeter (2005) similarly explicate that knowledge is a product of people's socio-cultural milieu.

An antithesis to the curriculum-in-context approach is the standardisation of the curriculum, which advocates a "one-size-fits-all" approach. The standardisation approach is non-responsive to the learners' context and delinks school education from their lived experiences, resulting in high levels of educational failure by pupils from marginalised backgrounds (UNESCO, 2009).

According to Banks and Banks (2010), a mainstream-centric curriculum impacts negatively on students who are outside the mainstream culture, by marginalising their experiences and cultures and neglecting their dreams, hopes and perspectives. Sleeter (2005) argues that a multicultural curriculum, in contrast, conceptualises students and their respective communities as sources and producers of knowledge and serves as a foundation on which to build new academic knowledge. Pinar (2003) also asserts that culture and identity are the fundamental concepts in multicultural curricular projects.

Multiculturalists propose adding or infusing contents about a cultural group as a remedy for the irrelevance of the school curricula. However, Banks (2006) argues that adding content about cultural groups and about women to the existing mainstream curriculum, and using an additive or an infusion approach, would not result in a change in the basic assumptions, perspectives, paradigms and values of the dominant curriculum.

Therefore, the indigenisation approach, as a solution to the question of relevance, is a favourable approach for curriculum studies and development, to ensure that it is relevant to the group it is intended to serve. We, therefore, turn our attention to the indigenisation discourses.

\subsection{The indigenisation discourses}

In this section the debate on the indigenisation discourses in the fields of social work and psychology is analysed in detail 
so as to take some lessons from it and incorporate them in curriculum studies and development.

The discourses on indigenisation in the field of social work criticise professional imperialism, question western values and theories, emphasise the importance of the indigenous social and cultural structures and stress the irrelevance of western theories and approaches developed in the metropolitan states in the western world and in non-western contexts (Tomaselli \& Shepperson, 1999; Yunong \& Xiong, 2008; \& Gray, 2010).

The failure of the indigenisation approach to change the original model's ingrained philosophy from the interventions in the recipient nations compelled the latter to generate the authentisation or culturally appropriate approach (Walton \& Abo El Nasr, 1988; Ferguson, 2005). This approach looks for the authentic roots in the local system to construct a domestic model in the light of the socio-cultural context.

In the field of psychology indigenisation is seen as a process of making knowledge culturally appropriate by transforming the transplanted or borrowed external elements, to make them suited to the local context (Sinha, 1997). As elsewhere, the indigenisation "from without" approach had failed in Philippines, leading to the adoption of another version of indigenisation, known as "indigenisation from within" or "cultural revalidation" (Pe-Pua, 2006).

Therefore, we argue that for "indigenisation from without" to materialise, there first has to be "indigenisation from within". This is due to the fact that unless the key cultural constructs are well identified, using indigenisation from within, it would be difficult to carry out indigenisation from without, which is a process by which foreign knowledge is made to pass through the culture of a given community to be utilised as valid knowledge.

We also want to draw into these discourses the different genres of the indigenisation approach.

\subsection{The different genres of the indigenisation approach}

In general, the approaches to indigenisation can be broadly categorised into three groups in respect of the relationship between western science and indigenous knowledge. These are: a complete break from western knowledge; blending western knowledge and indigenous knowledge; and restructuring or adapting the borrowed or inherited western knowledge.

Blyden (1969) is one of the African researchers who advocated complete cultural separation from the west in order to preserve, utilise and develop local traditions. In order to justify his argument, he indicated that Africa used to live in peace until it came into contact with Europeans. Thus, the only way to regain the lost innocence and peace in Africa, is to return to its original traditions and to restore its own institutions.

African-American researchers, who have realised the deficit and the subsequent irrelevance of the western education system to the African communities, have come up with an indigenisation approach that is a centric one that counters the western system. Such an indigenisation approach calls for a complete break from the Eurocentric curriculum and focuses on indigenous perspectives. This is known as Afrocentricity, African-centredness or Afrocentric pedagogy. We prefer to spell "Afrocentricity" "Africentricity". Africentricity, as a theory, is against racism, ignorance and mono-ethnic hegemony in the curriculum. It is a frame of reference where phenomena are viewed from the perspective of the African person (Asante, 1991, p. 171).

On the other hand, very recently, there emerged a group of researchers and political figures in Africa who suggested the blending of the positive aspects of indigenous knowledge with carefully selected and imported knowledge gained from western science and technology. The researchers, who favour this genre, are Tedla $(1992,1995)$, Shibanda (2006) and Shizha (2006). Salia-Bao (1989), although critical of borrowed and inherited curricula, also favours a blended approach, whereby indigenous culture is integrated into relevant aspects of western education.

Among the current African politicians who are in favour of a blended approach is the Tanzanian, Benjamin Mkapa (2004). He raises the idea that the Africans should not romanticise indigenous knowledge and consider global knowledge as irrelevant. He is convinced that sustainable development could be promoted if both indigenous and global knowledge are blended in a democratic and self-determined way.

Different researchers, for example Teklehaimanot (2000) and Bekele (2007), tried to convince the world that a blended approach works well by citing the experiences of Japan, the East Asian and Southeast Asian countries as examples of countries that have achieved economic development by blending western science and technology with their own cultural, historical and other heritages.

Whether Africa should continue to borrow from models that have worked well in other contexts or whether it should lay the foundation for devising a system that suits her well, is a question that needs to be answered. Of course, there may not be any problem with sharing the experiences of other contexts, if the sharing is done with proper care and is adapted to the context of the receiving country. However, we do not support the borrowing of experiences (biases and prejudices) from a knowledge system that undermines its counterpart and considers it retrogressive and unequal. Amare (1998) 
argues, in this regard, and with ample justification, for the necessity to narrow the gap between the cultural content of the borrower and that of the recipient or to find similarity in the strand of the two cultures to ameliorate the blending of knowledge systems.

The modernisation discourse openly calls for the complete replacement of the traditional values with the presumed universal western values and self-denial as a precondition for the modernisation and subsequent development of Africa (Amare, 1998; Tekeste, 2006; Bekele, 2007). However, both Amare (1998) and Bekele (2007) argue that the development endeavour of a given nation will succeed only through self-assertion or by enriching its own culture, rather than by the replacement of the own culture with an alien culture. Messay (2004) developed a new theory of modernisation, "Renovation of Tradition", which counters the hegemonic theory of modernisation. It calls for a return to Ethiopian traditions, rather than the wholesale adoption of western institutions and values in order to modernise.

Bekele (2007) calls for an intercultural approach that strikes the right balance between the exogenous and endogenous forms of knowledge. Unfortunately, intercultural dialogue can only take place when the two knowledge systems are on an equal footing and are ready for exchanges. Similarly, Janetius, Bekele and Mini (2008) suggest a bicultural approach known as acculturation, whereby a traditional cultural knowledge base is dug, identified, retained and integrated with specific forms and modalities which are selectively adopted from other cultures.

Yet another genre of indigenisation involves only restructuring or adapting the borrowed or inherited western methods, to make them suitable to the context. This approach reduces the marginalised groups to the level of the consumers of knowledge that has been produced elsewhere, rather than being producers of their own knowledge. One of the researchers who favour this approach is Hawi (2005).

In the field of social work, Gray and Coates (2010) argue that in its initial stage indigenisation has been seen as a process of importation and adaptation of western models of social work, mainly from the United State of America, to fit into non-western contexts, in other words, to make the imported knowledge fit the local contexts.

This researchers thoughts on these three approaches is that a complete-break approach will further marginalise the subordinate groups, as it will deny them the opportunity to learn from the knowledge has already been gained. If thoughtfully selected and imported, the global South can benefit a lot from western science and technology, as Japan, Eastern and Southeast Asia did. In addition, knowledge of the history of Ethiopia teaches us that this approach is detrimental to proper development. The Ethiopian medieval Emperor Fasiledes (reign 1632-1667) initiated a closed-door policy, whereby he barred all Europeans from entry into the Christian highlands. This policy kept Ethiopia isolated from the rest of the world for two centuries (Marcus, 1994, p. 40). This isolation denied Ethiopians the opportunity to learn from others and, thereby, hampered Ethiopia's development.

Vilakazi (1999) similarly argued against the complete-break approach, suggesting that Africa should not only be guided by the African past, and should not be closed to outside influences, since no civilisation has ever developed and prospered in isolation. He reiterates that the unique African pattern of development into modernity should base itself on the use of the resources provided by her civilisation, opening up to the finest influences resulting from cultural intercourse with other civilisations.

Restructuring or adapting borrowed or inherited western methods have also failed in the global South. After the sustained use of the indigenisation approach in their context, concerned researchers in the global South have come to realise its irrelevance and proposed a new approach of indigenisation that counters the earlier approach. The new approach is known as "indigenisation from within" or "cultural revalidation" and authentisation (Walton \& Abo El Nasr, 1988; Messay, 2004; Ferguson, 2005).

The researchers and politicians who favoured a blended approach have not made any kind of valid suggestions on how to blend the two knowledge systems. For us a blended approach is just like trying to mix oil and water. The western world and marginalised people everywhere have different philosophies of life and worldviews, hence, a different philosophy of education, which makes blending improbable. In addition, the educational knowledge of the marginalised indigenous people is underdeveloped, because of the onslaught of western knowledge, and whenever we try to blend them, there is a likelihood that the former will float above the latter, as oil floats on water.

Instead, indigenous knowledge should be allowed to stand on its own feet first, before any consideration is made to blend it with western science and technology (Yishak \& Gumbo, 2012). At present indigenous knowledge is not well established and is not on an equal level with the hegemonic western knowledge. Therefore, initially it would be fine if each knowledge system travelled on its own independent path, and later share the positive aspects of the two knowledge systems, on equal and democratic terms, by means of intercultural dialogue. Attempting to synthesise the two knowledge systems, before reconstructing and revalidating the marginalised indigenous knowledge systems, is like placing the proverbial cart before the horse.

We advocate a stand-alone approach until the local theories and epistemologies are well established, and then 
moving on to the blended approach that would promote intercultural dialogue. We suggest the blending of the two indigenisation approaches in different phases. In phase one we prefer the stand-alone indigenisation approach, which assists in grounding curriculum studies and development, providing indigenous foundations and theories, principles and ideas, derived from the culture. In phase two, the blended approach could be used to allow for an intercultural dialogue between indigenous and western knowledge.

An affirmation of the intercultural dialogue-approach in curriculum studies has been the new form of internationalisation of curriculum studies initiated by William Pinar (2010) in curriculum studies in South Africa. His approach entails a process of engaging nationally distinctive fields of curriculum studies in complicated conversation or dialogue with one another. For him internationalisation can provide scholars with a critical and intellectual distance from their own local cultures and from those standardising processes of globalisation.

The next section outlines the design of the study.

\section{Research Methodology}

We used a qualitative case study approach and design. Yin (2009) states that a contemporary phenomenon within a real life context could be the best case study method. Denzin and Lincoln (2005) declare that qualitative researchers study things in their natural settings. Thus, indigenising the basic education curricula, from an ethnic group perspective, is a contemporary phenomenon in the socio-cultural context of Ethiopia, which should be investigated in its natural setting. The case study can be some event or entity other than a single individual (Yin, 2009, p. 29). Yin holds the view that case studies could be done on decisions, programmes, implementation process and organisational change. Thus, constitutional, policy and strategy provisions that underpin the indigenisation of basic education from an ethnic group perspective in Ethiopia are decisions that could be investigated as a case study.

The case study method uses multiple sources of evidence, with data needing to converge in a triangulating fashion. This is done in order to make the data more manageable, because many more variables of interest emerge because of the richness of the phenomena being investigated (Yin, 2009, p. 2). In this study two sources of evidence were used, that is, in-depth interviews and document analysis. To facilitate the data gathering process, two data gathering instruments were designed, which are interview guide and document review guide.

The constitutional, policy and strategy documents were critically analysed so as to identify the conceptualisation of indigenisation advocated by the country's policy provisions using the document review guide. Six curriculum experts from the regional, zonal and woreda (regional) Education Bureaus of the Gamo Gofa Zone and Addis Ababa City Administration were selected by using the snowball or chain sampling method, in order to locate information-rich key informants or good interview participants (Patton, 2002). The curriculum experts, who are responsible for curriculum development, strictly follow the constitutional, policy and implementation strategy documents when preparing the curriculum for primary first-cycle education. Therefore, their experiences and perceptions of the provisions of these documents are crucial to corroborate the data obtained from the document analysis. The interviews were conducted faceto-face with the curriculum experts from June 1 to July 16 of 2013.

This study used a theory-based qualitative analysis (Patton, 2002). The data were analysed based on the critical theory of different genres such as multicultural theory, cultural relevant pedagogy, African critical theory and critical pedagogy. As Patton (2002) asserts, critical incidents or major events can constitute self-contained descriptive units of analysis. Thus, in this study the unit of analysis is the provisions of constitutional, policy and strategy documents.

One of the most important ethical principles of research is respecting the anonymity of the participants (Bogdan \& Biklen, 2007). To ensure the anonymity of the individuals who participated in the research, simple codes were used. The codes were prepared by merging letters and numbers. The representations of the designated codes are as follows: RGG1 stands for the first respondent from Gamo Gofa Zone and RAA1 stands for the first respondent from the Addis Ababa City Administration.

\section{Presentation and Analysis of Data}

This section critically examines the constitutional and policy provisions that align with the approach of indigenising the curricula. The within-case critical analysis of the data is offered and is compared to a review of related literature. Finally, recommendations for a policy revision are highlighted, in detail, with ample justifications for such a revision.

\subsection{Important constitutional and policy provisions}

\subsubsection{The 1994 Education and Training Policy}

The 1994 Education and Training Policy was adopted by the Transitional Government of Ethiopia, that succeeded the Derg regime, in order to address the complex educational problems that obstructed the country's education system. The 
policy began by acknowledging the lack of relevance of the country's education system, besides the other deficiencies. It gives due cognisance to the value of a relevant and appropriate education (Article 2.2.1).

Though the policy does not mention the word indigenisation or indigenous knowledge overtly, it covertly makes reference to them. It indirectly shows its concern for indigenous knowledge and an indigenisation approach in its various provisions. One of the salient provisions of the Education and Training Policy, which openly demonstrates the indigenisation approach, is the right accorded to the various nations and nationalities to use their languages as medium of instruction and textbook language in primary education and teacher training for kindergarten and primary education (Article 3.5.1; Article 3.5.3). In its bid to be fair and democratic, the Education and Training Policy gives special attention to the historically disadvantaged nationalities by providing them with compensation in order to increase their participation and enrolment in education (Article 3.9.4).

The other area where the Education and Training Policy tried to show fairness and support for democratic principles is in educational management. The policy has vested the responsibility of the administration of primary and secondary schools, as well as junior colleges, in the hands of regional states. It has also allowed parents or their representatives to play a prominent role in the administration of the schools. In addition, in the introductory part of the policy there is an emphasis on the development of culture in the content of education, curriculum structure and approach. One of the aims of education, envisaged in the policy, is to strengthen the local culture, starting from basic education through to tertiary levels. Education is also seen as an enabler that can help man to identify harmful traditions and replace them by useful ones.

The policy also calls for the development of the curriculum and preparation of textbooks, which should be based on sound pedagogical and psychological principles, are up to international standard, and give due consideration to concrete local conditions. From this provision it can be concluded that, from an indigenisation approach, the policy advocates for a blended approach, which takes into consideration both concrete local conditions and international standards.

The Education and Training Policy, in articles 2.2.8 and 3.6.7, views education as a supportive tool for developing traditional technology and for utilising modern technology. It provides that traditional education will be improved and developed by being integrated with modern education. This is an important provision, which gives due recognition to traditional knowledge and education. The policy favours the blending of traditional knowledge and education with modern knowledge and education in the country's education system.

\subsubsection{The 1995 Constitution of the Federal Democratic Republic of Ethiopia}

The 1995 Constitution of the Federal Democratic Republic of Ethiopia (FDRE) was ratified by the Constitutional Assembly, held on 08 December 1994. Members of the Constitutional Assembly were drawn from the elected representatives of the nations, nationalities and peoples of Ethiopia. The Constitution, in its preamble, expresses the conviction of the nations, nationalities and peoples of Ethiopia that they have been living with their rich and proud cultural legacies in territories they have inhabited for a long period and forged common interests and hold a common outlook through their continuous interaction.

One of the remarkable provisions of the 1995 Constitution, which aligns with the approach of indigenisation, is the provision accorded to local languages, culture and history. In article 5, sub-article 1, all Ethiopian languages are accorded the entitlement of enjoying equal state recognition. In article 39, sub-article 2, every nation, nationality and people in Ethiopia is granted the right to write and develop its own language and to express, develop and promote its culture and to preserve its history.

Article 51, sub-article 3 of the FDRE Constitution gives the federal government the mandate to establish and implement national standards and basic policy criteria for education and for the protection and preservation of cultural and historical legacies. The provision in article 52 , sub-article $2 \mathrm{c}$ confers powers to the regional states to formulate and execute economic, social and development policies, strategies and plans. Article 90, sub-article 2 of the FDRE Constitution assures the provision of education in a manner that is free from any religious influence, political partisanship or cultural prejudices.

The Federal Constitution, in article 91, sub-article 1 and 2, also assigns a duty on the federal government to support, on the basis of equality, the growth and enrichment of cultures and traditions that are compatible with fundamental rights, human dignity, democratic norms and ideals, and the provisions of the Constitution. The government and the Ethiopian citizens have the duty to protect the country's natural endowment, historical sites and objects.

\subsubsection{The 1997 Cultural Policy of the Federal Democratic Republic of Ethiopia}

The 1997 Cultural Policy was endorsed by the Council of Ministers of the FDRE in October 1997 as it was deemed 
necessary to put into effect the constitutional rights of the peoples of, which guarantee equal recognition and respect to the cultures of all the nations, nationalities and peoples of Ethiopia as enshrined in article 39, sub-article 2 of the 1995 Constitution of the Federal Democratic Republic of Ethiopia.

Two of the objectives (objective 1 and 5) of the Cultural Policy are directed towards giving equal recognition to all the different nations, nationalities and peoples of Ethiopia and to promote, preserve and pass on the culture and language of these respective groups to the next generation. Under section 9 of the general strategies for the implementation of the Cultural Policy, two strategies have been suggested with regard to the spread of cultural knowledge. These are the inclusion of cultural themes in the educational curricula, with the aim of integrating education with culture and thereby to shape the youth with a sense of cultural identity; and the transmission of educational programmes that reflect the various cultures of the country through the mass media institutions in order to promote the cultural knowledge of the people of Ethiopia. These strategies have a direct bearing on the education system and the curricula.

One of the objectives (objective 9) of the policy also provides room for intercultural dialogue, on the basis of the equality of cultures, for their mutual benefit. This provision should help to maintain internal cohesion in the country by allowing intercultural dialogue among the different cultures. If implemented properly, this provision would provide the previously marginalised cultural groups the opportunity to develop their culture and language so that it will have a status equivalent to that of the dominant cultural groups. By doing this it can promote mutual respect and social justice among the different cultural groups.

\subsubsection{The 2001 Revised Constitution of the SNNPR State}

The Constitution of the Southern Nations, Nationalities and Peoples Regional State (like the Federal Constitution) to which the Gamo Gofa Zone is situated comprises a provision which favours the indigenisation from ethnic group's perspective.

The 2001 Revised Constitution of the Southern Nations, Nationalities and Peoples' Regional State has been endorsed by the SNNPR State Council of Nationalities. Article 39, sub-article 1, of the Constitution grants every nation, nationality and people in the region equal opportunity to preserve its identity and have it respected, to promote and preserve its heritage, artefacts and history, and to use and develop its own language and culture so that there would be no dominant and subordinate groups. It also paves the way for the reign of social justice in the region.

\subsubsection{The 2002 Implementation Strategy Document of the Education Policy}

The implementation strategy document has been prepared by the Federal Ministry of Education to execute the provisions of the Education and Training Policy of 1994. The strategy begins by admitting the fact that the curricula and education system of the former regimes were borrowed or inherited either from the western or eastern world since it ignored the concrete conditions of the country and, thus, became non-responsive to the needs and problems of the country (MOE, 2002, p. 14). The strategy document clearly spelled out the ethnic domination of the Amhara over the other ethnic groups in the country during the previous regimes. The main evidence of this in the document is the deliberate imposition of Amharic as the medium of instruction at primary education level throughout the country and in the content of the educational materials, which glorifies the attributes, contributions, customs, culture, and history of one group and downplays the qualities and cultural attributes of other nationalities (MOE, 2002, p. 13-14).

Thus, the MOE supported, as one of its educational strategy missions, the removal of fundamental obstacles that stand in the way of quality and relevant education. In order to accomplish this mission, the MOE decided to change the curriculum; provide sufficient educational materials and equipment; and improve the quality and quantity of teacher training (MOE, 2002, p. 23).

The anti-democratic nature of the educational administration during the former regimes can be clearly identified in the implementation strategy. The administration of education was centrally controlled. In order to resolve this problem, the organisation of education was decentralised by the current administrators and responsibility was delegated to the various levels of regional and local administrations. The regional educational institutions were tasked with the responsibility of designing a primary education curriculum that reflects the region's specific needs and culture (MOE, 2002, p. 56-57).

In order to realise the twin purposes of democratisation of the educational content and the provision of quality and relevant educational services, the strategy called for a change of the curriculum. A new educational curriculum was developed in which special attention was paid to how the content would relate to the concrete conditions of the country. Based on this curricular principle, primary school textbooks were prepared, taking the realities of the specific region and 
the culture and achievements of the local populations into consideration (MOE, 2002, p. 30). In addition, the contents of the curriculum were adapted to reflect the principle of respect for the true realities, values and identities of all nations, nationalities and peoples in accordance with the principle of equality of citizens (MOE, 2002, p. 33).

The strategy recognises the connection between education and society's cultural, economic and political realities and activities and accepts this connection as one of the pillars of quality education. Thus, quality is implicated in students receiving education in their mother tongue, in the upliftment of their respective languages, in the equitable distribution of educational services and by ensuring that the relatively poorer and backward areas are widely covered by such services (MOE, 2002, p. 71).

The strategy gave schools the mandate to pass on to each new generation the leading values and thoughts of the society. Hence, schools are said to have fulfilled their central and chief mission only when they have succeed in transmitting to the next generation the political, social, and economic values of the society and, thereby, produce citizens capable of playing a positive role in their community at large (MOE, 2002, p. 35).

\subsection{The salient features and limitations of the provisions}

The critical analysis of the constitutional and policy documents singled out notable provisions that overtly and covertly support the indigenisation approach and identified limitations contained in these documents that are the antithesis of indigenisation approach. Therefore, this section is devoted to critically analysing these salient features and limitations of the constitutional and policy provisions in the light of the literature reviewed and in context of the theoretical and conceptual framework discussed. The country's constitutions and policies have a number of salient provisions that supports the indigenisation approach. These salient features of the constitutional and policy provisions are the use of local languages as the medium of instruction and textbook language, the compensatory measure to increase the participation and enrolment in the education of the historically disadvantaged nationalities, and the development of culture in the content of education, curriculum structure and approach. These features are discussed in detail below.

\subsubsection{The use of local languages as medium of instruction and textbook language}

The use of local languages as the medium of instruction and textbook language in primary education and teacher's training for kindergarten and primary education is one of the salient features of the Education and Training Policy that support the indigenisation approach. The Cultural Policy also has a similar provision, which grants the different nations, nationalities and peoples of Ethiopia the right to equal recognition, and the right to promote and preserve their languages and to pass it on to the next generation. The Implementation Strategy attaches a high value to the students' learning in their mother tongue.

A review of related literature on the research problem conveys the message that language is the medium through which the content of ethnicity, culture and identity of a group is formed and transmitted to its offspring (Banks, 2006). One's language is vital for understanding the cultural reality that frames one's life and reflecting one's attitude toward its physical environment (Shizha, 2005; Banks, 2006). It has been proven scientifically that there is no language that can replace the child's mother tongue in providing her/him with a proper education. The production and transmission of knowledge in their own language promotes the transformation of a community (Bekele, 2007). Shizha (2007) asserts that language is a vital component for incorporating indigenous knowledge and culture into the school curriculum.

However, one of the criticisms directed at African schools is the use of a medium of instruction which lacks Africanness and African rationality, that alienates students from their local communities, disrupts the teaching and learning process and hampers students' cognitive development and learning outcomes (Shizha, 2005, 2007). Thus, the policy provision which sanctions the use of the mother tongue as the medium of instruction is a critical one in that it would facilitate the indigenisation approach in curriculum studies and development and, thereby, help with the incorporation of the culture and heritage and the subsequent transformation of the marginalised Gamo ethnic group.

This provision has been applauded by the interviewees from the Gamo Gofa Zone. Interviewee RGG1 expressed his view as follows:

The right as a provision is a scientific one which aligns with internationally accepted principles. The mother tongue for the children of the Gamo ethnic group is Gamotso language. Thus, enabling students to learn through their vernacular language is by itself a success or victory. I say this because learning in the language one knows very well than struggling to learn through a language which he does not know lightens the burden of learning.

Interviewee RGG2 also observed the alignment of the policy provisions with the inalienable human rights bestowed on human beings like this: 
What the policy provided is the right which is granted to human beings by nature and inalienable. It is not something which should be considered as a gift from anybody. The right given to the Gamo ethnic group to learn through the medium of its vernacular language is a proper right.

Interviewee RGG3 stated her view about the policy provision by comparing it with what prevailed in the past in the following way:

Now we are granted the right to speak in our language and publicly use the language as working language and preserve our culture. In the past a person who speaks Gamo language was not seen as equal with a person who speaks Amharic language due to the prevailing perception. The policy has provided us with the opportunity to disclose our identity ... the right to reflect our identity has been granted and this shows the significance of the provisions of the present policy.

However, all the interviewees reflected that the intentions of the policy documents are not properly implemented by the various government structures assigned to this purpose. The medium of instruction for the children of the Gamo ethnic group in Gamo Gofa Zone is the Gamotso language and this, in itself, is a victory. But the message being communicated at school level, through the hidden curriculum, is so pervasive that students do not have the confidence to publicly speak or to develop the local language. The working language and medium of communication at schools is still Amharic.

This provision has also been praised by the interviewees from the Addis Ababa City Administration. Interviewee RAA1 expressed his view on the policy like this:

One of the pillars of the policy provision is providing primary first-cycle education through the medium of mother tongue. This provision has basic deviation from the policies of the previous regimes. The provision of learning using a vernacular language is a right provision in terms of social, economic and political equity... The policy supports responsiveness to the culture, language, and identity of the Gamo ethnic group in the process of curriculum development. Interviewee RAA2 similarly expressed a positive view of the policy provisions:

I see the policy provisions as an affirmative move. This is because the culture, language, and identity of one ethnic group are part and parcel of the overall culture, language, and identity of the country and its heritage. If you take the language, culture, and history of the Gamo, Tigray and other ethnic groups from the SNNPR it represents the language, culture, and history of the country as a whole.

Interviewee RAA3 stated his view about the policy provision in terms of international reputation in the following way:

The Ethiopian education policy is a policy which won the admiration of professionals internationally. However, there could be problem with implementation and the policy is accorded an international recognition and when I see it from different angles the policy is free from problems.

However, the interviewees argued that there are weaknesses with implementation of the intentions of the policy in the Addis Ababa City Administration. The curriculum framework, at least theoretically, provides room for the provisions of the policy. Unfortunately, as stated above, the provisions of the policy have not been fully materialised in the curriculum development process in the Addis Ababa City Administration. The use of mother tongue as the medium of instruction and textbook language for primary first-cycle education has not been realised.

The interviewees, both from the Gamo Gofa Zone and the Addis Ababa city Administration, have not had a close and critical look at the provisions of the constitution, policy and strategy of the post 1994 era. They consider the provisions of the constitution, policy and strategy as infallible, but they attach the prevailing problem related to properly indigenising the primary first-cycle curriculum to the implementation of the provisions. Their argument is justified when they mention that the curriculum framework is centrally prepared to ensure standards throughout the country. However, the main source of the national curriculum framework is the standardisation thesis which is contained in the constitution, policy and strategy documents themselves.

\subsubsection{The compensatory measure to the historically disadvantaged nationalities}

The second important provision of the Education and Training Policy, which is an affirmation of critical theory, is the anticipated compensatory measure, which would increase the participation and enrolment in education of the historically disadvantaged nationalities. The Implementation Strategy also adopted a new approach which decentralised the organisation of education and delegates responsibility to the various levels of regional and local administrations.

The postmodern critical perspective advocates that the main task of the curriculum development scholars, in this era, is the empowering of teachers, peasants, students and labourers to become leaders of emancipatory education and a liberated community. It also envisions a democratic education, which provides hope for all teachers and students 
regardless of race, class, religion, gender, sexuality, language, ability, ethnicity or age (Slattery, 2006). Indigenisation projects seek to eliminate all types of oppression, counteract assimilative education and ensure the equal representation of all groups in the curriculum (Ismailova, 2004). Thus, the enhancement of the participation and enrolment in education of the historically disadvantaged nationalities covertly affirms the indigenisation approach.

Redress of structural inequalities related to identity groups is a central principle which underpins multicultural education (Bennett, 2011). This redress will counter the deep-seated structural injustices and systemic patterns of dominance and suppression that privilege dominant groups and deny the marginalised groups economic and political equality in a society (Bennett, 2011). Thus, the provision is consistent with the tenets of multicultural education and the indigenisation approach and very necessary for ensuring social justice in a given society.

Although they praised the rights conferred on the local administration to develop a curriculum, run the education and teacher's training for primary first cycle education, the interviewees from the Gamo Gofa Zone expressed their criticism of the various government structures for their failure to properly implement the intentions of the policy documents.

Interviewee RGG1 stated the failure of those who are in the government structure to properly implement the policy provisions like this:

The significance of the provisions of the policy is clearly known by those who work in Education Departments starting from Zone to Woreda level. Since they are drawn from the ethnic group they have to foresee the mechanisms which help materialize the provisions of the policy. ... the government made a provision in policy documents but those in the government structure are not implementing the provisions properly.

Interviewee RGG2 explained how the responsibility hinges on the members of the ethnic group to properly translate the provisions like this:

The provision is proper, timely and conducive to the people. In the past many people had fought for this right. But we are the ones who should develop our education system based on this noble provision. We have to comment on when we see problems in it.

Interviewee RGG3 similarly stated how the prime responsibility rests on members of the ethnic group to exploit the opportunity in the following way:

Therefore, these things provide us good opportunity to resume the use of the Gamotso language as a working language in offices. That opportunity went out of our hands and now the time is coming for it to return back in to our hands. ... If all members of the ethnic group do their part there is no way that the Gamo culture will remain unknown to others. The most important thing is our determination. If we use our skill and knowledge fully we will achieve this target.

\subsubsection{The development of culture in the content, curriculum structure and approach}

The development of culture in the content of education, curriculum structure and approach is another notable provision of the Education and Training Policy. The Cultural Policy's strategies call for the inclusion of cultural themes into the educational curricula and the transmission of educational programmes that reflect the various cultures of the country. The Implementation Strategy attaches education quality to the education's connection with the society's cultural, economic, and political realities and activities. It also suggests the democratisation of educational content and the provision of educational services by changing the existing curriculum.

Gay (2000) asserts that a relevant curriculum is supposed to include information about the histories, cultures, contributions, experiences, perspectives and issues of the students' respective ethnic groups. According to Pinar (2003) and Bennett (2011), multicultural curricular projects are ideal for students who come from different ethnic groups, because they are attentive to students' own culture, history and identity. A multicultural curriculum conceptualises students and their respective communities as sources and producers of knowledge and serves as a foundation on which to build new academic knowledge (Sleeter, 2005). The approach of indigenising curricula also calls for anchoring on traditions in order to develop locality-specific paradigms (Dominelli, 2005).

This policy provision is noble in that it goes beyond the common approach of adding or infusing cultural contents, which had been strongly criticised by Banks (2006). It calls for the development of culture in the curriculum structure and approach. Thus, the provision could help in countering the basic assumptions, perspectives, paradigms and values of the dominant mainstream curriculum. If its intentions are properly translated in implementation, it can also promote the development of relevant curricula that aligns with the socio-cultural and structural context of the Gamo ethnic group in the country.

The remarkable provisions of the Federal and Regional Constitutions are aligned to the indigenisation approach. Such provisions include equal rights granted to every nation, nationality and people in Ethiopia to preserve their identity 
and have it respected, promote and preserve its heritage, artefacts and history, and use and develop its own language and culture. This is a noble provision which ensures social justice and equality critical education is committed to.

\subsection{Limitations of the constitutional and policy provisions}

Based on the findings, we suggest that some of the country's constitutional and policy provisions are against the indigenisation thesis. These provisions are the following:

\subsubsection{The standardisation thesis}

The Federal Constitution gives the federal government the mandate to establish and implement national standards and basic policy criteria for education to be observed by regional states, while formulating and executing state policies. The right which is conferred on regional states to formulate and execute regional policies has been systematically restricted by the national policy standards and criteria. Even the federal government went beyond the right and duty conferred on it by the Federal Constitution and adopted the 1994 Education and Training Policy and the 1997 Cultural Policy, which have been interpreted by the regional governments, not as policy criteria or standard, but as policies that should be implemented as they are. By doing this, the federal government denied the regional governments the right to adopt policies appropriate for their local context.

Another tool which has been used to maintain standards and, thereby show strict adherence to the standardisation thesis in the country, is the curriculum framework. As both interviewees from the Gamo Gofa Zone and the Addis Ababa City Administration argued, the curriculum standard has been maintained through the curriculum framework, which is prepared at federal level by the MOE. The interviewees further reiterated accommodating the Gamo culture and heritage in the curriculum could be possible only during the time of preparation of the curriculum framework. This is due to the fact that regions would not entertain issues that have not been addressed in the national standard. They interpret their role as restricted to the preparation of textbooks to ensure that it strictly aligns with the curriculum framework.

The standardisation thesis is an antithesis of indigenisation, non-responsive to learners' context and creates a mismatch between what pupils learn and what they live. As a result, the approach leads pupils from marginalised backgrounds to high levels of educational failure by delinking school education with their own experiences (UNESCO, 2009). The standardisation thesis was devised by the western world to sustain its dominance and impositions on the marginalised communities. Concrete local conditions cannot be properly treated in curriculum development and textbook preparation when the standardisation thesis is applied.

\subsubsection{The blended indigenisation approach}

The other limitation of the Education and Training Policy is its call for the blending of traditional knowledge and education with modern knowledge and education in the country's education system. Though the provision is important in its own right, it has limitation.

Different African scholars, such as Bekele (2007), Mkapa (2004), Salia-Bao (1989) and Shibanda (2006), favour the blended approach, which integrates indigenous knowledge and education with the relevant aspects of western knowledge and education, as a viable approach that would serve as a stimulant for economic growth in Africa. However, as Amare (1998) suggests, for synthesis or blending to take place there has to be similarity in the strand of the two cultures or a narrower gap between the cultural content of the borrower and the recipient.

We hold the view that a stand-alone indigenisation approach that calls for curriculum studies and development on indigenous foundations and theories, principles and ideas derived from the culture is a viable approach of curriculum studies and development in Ethiopia. Once this has been satisfied, then a blended approach which allows an intercultural dialogue among equals can be considered. As was mentioned earlier in the paper, we strongly believe that indigenous knowledge is not well established and is not on par with the dominant mainstream knowledge, therefore, blending under such circumstances would be disadvantageous. Thus, the country's policies and strategies have to be rectified, to include this approach, and ensure the successful implementation of the new indigenisation approach.

\subsection{Policy implications of the findings}

The major findings of the study have a bearing on the Ethiopian constitution and its policy and strategy documents. The salient provisions, which promote the indigenisation of the curriculum, have to be maintained as they are. 
The imposition of the federally adopted policies, strategies and curriculum framework on the regional states and compliance to the policy standards hampered the development of culturally relevant curricula in the regions. Indigenising the curricula, from an ethnic group perspective, can only happen if this noble right, conferred on regional states, is respected.

The constitutional, policy and strategy documents' salient provisions have been diluted by the open support for the standardisation thesis and blended indigenisation. By doing this, they have tried to mix two opposing paradigms, indigenisation and standardisation, which do not work together. Thus, the documents have to favour either the indigenisation thesis as stated in 4.3.2 above. or the standardisation thesis.

\section{Conclusion and Recommendations}

There are notable provisions that overtly and covertly support the indigenisation approach. The use of local languages medium of instruction and textbook language and teacher's training for kindergarten and primary education are notable provisions of the Education and Training Policy. They are the compensatory measure to increase the participation and enrolment of the historically disadvantaged nationalities in education, and the development of culture in the content of education, curriculum structure and approach.

However, there are still provisions that are against the indigenisation thesis. These are the standardised thesis and the blending approach. By first adopting a stand-alone indigenisation approach and then, subsequently, embracing a blended approach, which allows an intercultural dialogue among equals, is a viable approach to curriculum studies and development in Ethiopia. This would ensure that the education system is relevant for the indigenous peoples. Therefore, there is a need for the re-conceptualisation of the indigenisation approach in the country's policies and strategies, that is, if authorities want to ensure that the curriculum is relevant to the structural and socio-cultural context of the country.

\section{References}

Abdi, A. A. (2009). Educating for social development in sub-Saharan Africa: reconstructing the philosophical and epistemological foundations. Paper presented at the 1st International Conference on Educational Research for Development. Addis Ababa, Ethiopia.

Alangui, W. V. (1999). Indigenous peoples and education: contextualizing education. Tebtebba Briefing Paper. No. 4. Baguio City: Tebtebba Foundation.

Amare, A. (1998). Culture and development. IER Flambeau, 5(1), 1-5.

Amare, A. (2009a). From knowledge acquisition to knowledge application: the case of curriculum inquiry in Ethiopia. Paper presented at the 1st International Conference on Educational Research for Development. Addis Ababa, Ethiopia.

Amare, A. (2009b). Higher education curriculum relevance and educational inputs. Addis Ababa: FSS.

Asante, M. K. (1991). The Afrocentric idea in education. The Journal of Negro Education, 60(2), 170-180.

Banks, J. (2006). Cultural diversity and education: foundations, curriculum and teaching. 5th edition. San is a viable approach of curriculum studies and development in Ethiopia Francisco: Pearson Education.

Banks, J. \& Banks, C. (2010). Multicultural education: issues and perspectives is a viable approach of curriculum studies and development in Ethiopia. 7th edition. New York: Wiley \& Sons.

Bekele, G. (2007). Extraversion and the goal of education in the African context. African Study Monographs, 28(3), 107-123.

Bennett, C. I. (2011). Comprehensive multicultural education: theory and practice. 7th edition. Boston: Pearson Education.

Blyden, E. W. (1969). African life and customs. London: African Publication Society.

Bogdan, R. C., \& Biklen, S. K. (2007). Qualitative research in education: an introduction to theories and methods. 5th edition. Boston, MA: Pearson Education.

Cornbleth, C. (1990). Curriculum in context. London: The Flamer Press.

Dei, G. (2008). Possibilities in African schooling and education. In Dlamini, S. (ed.). New directions in African education: Challenges and possibilities. Calgary: Calgary Press.

Denzin, N. K. \& Lincoln, Y. S. (2005). Introduction. In Denzin, N. K. \& Lincoln, Y. S. (eds.). The Sage handbook of qualitative research. 3rd edition. Thousand Oaks, CA: Sage.

Dominelli, L. (2005). News and views from IASSW: International social work: themes and issues for the 21st century. International Social Work, 48(4), 504507.

FDRE. (1995). The Constitution of the Federal Democratic Republic of Ethiopia. Addis Ababa: FDRE Council of Peoples' Representatives.

FDRE. (1997). The Federal Democratic Republic of Ethiopia Cultural Policy. Addis Ababa: Berhanena Selam Printing Enterprise.

Ferguson, K. M. (2005). Beyond indigenization and reconceptualization: towards a global, multidirectional model of technology transfer. International Social Work, 48(5), 1-17.

Gay, G. (2000). Culturally responsive teaching: theory, research and practice. New York: Teachers College Press.

Girma, M. (2012). Cultural politics and education in Ethiopia: a search for a viable indigenous legend. Journal of Politics and Law, 5(1), 117-125.

Gray, M. (2010). Indigenization in a globalizing world: a response to Yunong and Xiong (2008). International Social Work, 53(1), $115-127$.

Gray, M. \& Coates, J. (2010). Indigenization and knowledge development: extending the debate. International Social Work, 53(5), 613-627.

Habtu, A. (2003). Ethnic federalism in Ethiopia. Paper presented at the Second EAF International Symposium on Contemporary Development Issues in Ethiopia. Addis Ababa, Ethiopia.

Hawi, H. (2005). A search for an alternative Afro-centric development theory. [Online] Retrieved April 4, 2008 from www.codesria.org/Links/conferences/general_assembly11/papers/hawi.pdf.

Ismailova, B. (2004). Curriculum reform in post-Soviet Kyrgyzstan: indigenization of the history curriculum. The Curriculum Journal, 15(3), $247-264$.

Janetius, T., Bekele, W. \& Mini, T. (2008). Indigenizing knowledge base for consequential education in Ethiopia. Paper presented at the Conference of Dilla 
University. Dilla, Ethiopia.

Kassam, A. (2002). Ethnotheory, ethnopraxis: ethnodevelopment in the Oromia regional state of Ethiopia. In Sillitoe, P., Bicker, A. \& Pottier, J. (eds.). Participating in development: Approaches to indigenous knowledge. London: Routledge.

Kincheloe, J. L. (2006). How did this happen? The right-wing politics of knowledge and education. In Steinberg, S. R. \& Kincheloe, J. L. (eds.). What you don't know about schools. New York: Palgrave Macmillan.

Kincheloe, J. L. (2008). Knowledge and critical pedagogy: an introduction. Montreal: Springer.

Kisanji, J. (1995). The relevance of indigenous customary education principles in the formulation of special needs education policy. Paper presented at the Fourth International Special Education Congress. Birmingham, United Kingdom.

Lovise, A. (2011). The politics of ethnicity in Ethiopia: actors, power and mobilisation under ethnic federalism. Danvers, MA: Koninklijke Brill NV.

Maaza, B. (1966). A study of modern education in Ethiopia: its foundations, its development, its future, with emphasis on primary education. Unpublished PhD thesis. Columbia: Columbia University.

Manuwuike, E. (1978). Dysfunctionalism in African education. New York: Vintage Press.

Marcus, H. G. (1994). A history of Ethiopia. Berkeley: University of California Press.

Messay, K. (2004). Africa's quest for a philosophy of decolonization. Amsterdam-New York: Rodopi.

Mkapa, B. (2004). Introduction: Local pathways to global development. In Woytek, R., Shroff-Mehta, P. \& Mohan, P. C. (eds.). Indigenous knowledge: local pathways to global development. Washington D.C.: The Africa Region's Knowledge and learning Group.

MOE. (1972). Challenge to the nation. Report of the Education Sector Review. Addis Ababa: Ministry of Education.

MOE. (2002). Education and training policy and its implementation. Addis Ababa: Mega Publishing Enterprise.

MOE. (2010). Education Sector Development Program IV: Program Action Plan. Addis Ababa: Ministry of Education.

Obanya, M. (1999). The dilemma of education in Africa. Dakar: UNESCO.

Patton, M. (2002). Qualitative research and evaluation methods. 3rd edition. Thousand Oaks, California: Sage Publications.

Pe-Pua, R. (2006). From decolonizing psychology to the development of a cross-indigenous perspective in methodology: the Philippine experience. In Kim, U., Yang, K. \& Hwang, K. (eds.). Indigenous and Cultural Psychology. New York: Springer Media.

Pinar, W. F. (2003). Introduction: In Pinar, W. F. (ed). International handbook of curriculum research. New Jersey: Lawrence Erlbaum.

Pinar, W. F. (2010). Introduction. In: Pinar, W. F. (ed.) Curriculum studies in South Africa: intellectual histories and present circumstances. New York: Palgrave Macmillan.

Rabaka, R. (2009). Africana critical theory: reconstructing the black radical tradition, from W. E. B. Du Bois and C. L. R. James to Frantz Fanon and Amilcar Cabral. Plymouth: Lexington Books.

Rankopo, M. \& Osei-Hwedie, K. (2011). Globalization and culturally relevant social work: African perspectives on indigenization. International Social Work, 54(1), 137-147.

Roschanski, H. (2007). Deprived children and education: Ethiopia. Amsterdam: IREWOC.

Salia-Bao, K. (1989). Curriculum development and African culture. London: Edward Arnold.

Shibanda, G. (2006). University perspectives in African indigenous knowledge management. A paper presented at the World Library and Information Congress: 72nd IFLA General Conference and Council. Seoul, Korea.

Shiundu, J. \& Omulando, S. (1992). Curriculum theory and practice in Kenya. Nairobi: Oxford University Press.

Shizha, E. (2005). Reclaiming our memories: The education dilemma in postcolonial African school curricula. In Abdi, A. \& Cleghorn, A. (eds.). Issues in African education: sociological perspectives, edited by A. Abdi and A. Cleghorn. New York: Palgrave Macmillan.

Shizha, E. (2006). Legitimising indigenous knowledge in Zimbabwe: a theoretical analysis of postcolonial school knowledge and its colonial legacy. Journal of Contemporary Issues in Education, 1(1), 20-35.

Shizha, E. (2007). Critical analysis of problems encountered in incorporating indigenous knowledge in science teaching by primary school teachers in Zimbabwe. The Alberta Journal of Educational Research, 53(3), 302-319.

Sinha, D. (1997). Indigenizing psychology. In: Berry, J., Poortinga, Y. \& Pandey, J. (eds.) Handbook of cross-cultural psychology: theory and method, Volume 1. 2nd edition. Boston: Allyn and Bacon.

Slattery, P. (2006). Curriculum development in the postmodern era. 2nd edition. New York: Routledge Taylor \& Francis.

Sleeter, C. E. (2005). Un-standardizing curriculum: multicultural teaching in the standards-based classroom. New York: Columbia University.

SNNPR. (2001). The revised constitution, 2001 of the Southern Nations, Nationalities, and Peoples' Regional State. Awassa: SNNPR State Council of Nationalities.

Solomon, A. (2008). Policy formulation, curriculum development and implementation in Ethiopia. Addis Ababa: The Book Centre of Addis Ababa University.

Tedla, E. (1992). Indigenous African education as a means for understanding the fullness of life: Amara traditional education. Journal of Black Studies, 23(1), 7-26.

Tedla, E. (1995). Sankofa: African thought and education. New York: Peter Lang.

Tekeste, N. (1990). Crisis of Ethiopian education: some implications to nation-building. Uppsala: Uppsala University Press.

Tekeste, N. (1996). Rethinking education in Ethiopia. Uppsala: Nordiska Afrikainstituet.

Tekeste, N. (2006). Education in Ethiopia: from crisis to the brink of collapse. Stockholm: Nordiska Afrikainstituet.

Teklehaimanot, H. (1999). The cultural foundation of education in Ethiopia. IER Flambeau, 7(1), 1-10.

Teklehaimanot, H. (2000). The role of education in the challenge of underdevelopment syndrome of Africa: a lesson from the Orient. IER Flambeau, 8(1), 113.

Temechegn, E. (2000). What research says about African science education. IER Flambeau, 8(1), 15-28.

TGE. (1994). Education and Training Policy. Addis Ababa: St. George Printing Press.

Tomaselli, K. \& Shepperson, A. (1999). Media studies and practice reborn: recovering African experiences. In Makgoba M. W. (ed.). African renaissance: the new struggle. Cape Town: Mafube Publishers.

UNESCO. (2009). Investing in cultural diversity and intercultural dialogue. Paris: UNESCO.

Vilakazi, H. W. (1999). The problem of African universities. In Makgoba M. W. (ed.). African renaissance: the new struggle. Cape Town: Mafube Publishers.

Walton, R. \& Abo El Nasr, M. (1988). Indigenization and authentization in terms of Social Work in Egypt. International Social Work, 31(2), 135-144.

Woube, K. (2004). The need for analyzing culture in planning curriculum. IER Flambeau, 11(2), 13-32.

Yin, R. (2009). Case study research: design and methods. 4th edition. Thousand Oaks, CA: Sage.

Yishak, D. \& Gumbo, M.T. (2012). Indigenizing the school curriculum: an alternative approach for ensuring relevance to the context. Indilinga - African Journal of Indigenous Knowledge Systems, 11(2), 179-193.

Yunong, H. \& Xiong, Z. (2008). A reflection on the indigenization discourse in Social Work. International Social Work, 51(5), 611-622. 